\title{
Correction to: Determination of fluoroquinolones in food samples by magnetic solid-phase extraction based on a magnetic molecular sieve nanocomposite prior to high-performance liquid chromatography and tandem mass spectrometry
}

\author{
Hao $\mathrm{Yu}^{1} \cdot$ Yuqian Jia ${ }^{1} \cdot \mathrm{Ri} \mathrm{Wu}^{2} \cdot$ Xiangfeng Chen ${ }^{1,2} \cdot \mathrm{T}$.-W. Dominic Chan ${ }^{2}$ \\ Received: 18 December 2020 / Accepted: 18 December 2020 / Published online: 7 January 2021 \\ (C) Springer-Verlag GmbH Germany, part of Springer Nature 2021
}

Correction to: Analytical and Bioanalytical Chemistry. https://doi.org/10.1007/s00216-019-01726-0

The authors would like to call the reader's attention to the fact that, unfortunately, there was a mistake regarding grant numbers in the Acknowledgments of this manuscript; please find the correct information below.

Financial support from the Natural Science Foundation of Shandong Province (ZR2017MB011), the Research Grant Council of the Hong Kong Special Administrative Region (Ref. 2130475 and 4441627), and the Key R\&D Program of Shandong Province (2017CXGC0223) are gratefully acknowledged.

Publisher's note Springer Nature remains neutral with regard to jurisdictional claims in published maps and institutional affiliations.

The online version of the original article can be found at https://oi.org/ 10.1007/s00216-019-01726-0

\footnotetext{
Xiangfeng Chen

xiangfchensdas@163.com

$\triangle$ T.-W. Dominic Chan twdchan@cuhk.edu.hk

1 Key Laboratory for Applied Technology of Sophisticated Analytical Instruments, Shandong Analysis and Test Centre, Qilu University of Technology (Shandong Academy of Sciences),

Jinan 250014, Shandong, China

2 Department of Chemistry, The Chinese University of Hong Kong, Hong Kong SAR, China
} 